\title{
Reduced serum paraoxonase I (PONI) activity in patients with schizophrenia treated with olanzapine but not quetiapine
}

This article was published in the following Dove Press journal:

Neuropsychiatric Disease and Treatment

10 October 2013

Number of times this article has been viewed

\section{Cüneyt Ünsal' \\ Yakup Albayrak' \\ Neslihan Albayrak ${ }^{2}$ \\ Murat Kuloğlu ${ }^{3}$ \\ Kenji Hashimoto ${ }^{4}$ \\ 'Department of Psychiatry, Namik Kemal University, School of Medicine, Tekirdağ, Turkey; ${ }^{2}$ Department of Cardiology, Kirklareli State Hospital, Kirklareli, Turkey; ${ }^{3}$ Department of Psychiatry, Akdeniz University School of Medicine, Antalya, Turkey; ${ }^{4}$ Division of Clinical Neuroscience, Chiba University Center for Forensic Mental Health, Chiba, Japan}

Background: Second generation antipsychotics (SGAs) are currently the most prescribed drugs in the treatment of schizophrenia. Despite their advantages, which include greater improvement in negative symptoms, cognitive function, prevention of deterioration, quality of life, and fewer extrapyramidal symptoms, the concern regarding metabolic abnormalities which might cause cardiovascular diseases during treatment with SGAs have been rising. Paraoxonase 1 (PON1) is an enzyme mostly located on high-density lipoprotein particles, and has been shown to protect or inhibit lipoprotein oxidation. Growing evidence suggests that PON1 plays a key role in the pathophysiology of atherosclerosis.

Methods: In the present study, we measured serum PON1 activity and serum levels of total cholesterol (TC), triglyceride, high-density lipoprotein cholesterol (HDL-C), and low-density lipoprotein cholesterol (LDL-C) in patients with schizophrenia, who had been treated with either olanzapine or quetiapine, and in healthy controls. Thirty five patients who had been treated with olanzapine, 29 patients who had been treated with quetiapine, and 32 age, sex, and smoking status-matched healthy control (HC) participants were enrolled. Serum PON1 activity and serum levels of TC, triglyceride, HDL-C, and LDL-C were measured.

Results: Serum PON1 activity in the olanzapine group was significantly lower than that of $\mathrm{HC}$ and quetiapine groups. Furthermore, serum levels of TC and LDL-C in the olanzapine group were significantly higher than those of quetiapine and $\mathrm{HC}$ groups. Interestingly, there was a positive correlation between PON1 activity and HDL-C levels in the olanzapine group.

Conclusion: These findings suggest that serum PON1 activity in patients treated with olanzapine was lower than that of $\mathrm{HC}$ and quetiapine groups, and that PON1 may play a role in the metabolic side effects associated with olanzapine treatment. A further study to examine the relationship between serum PON1 activity and cardiovascular and metabolic side effects during treatment with SGAs will be of great interest.

Keywords: second generation antipsychotics, SGA, atherosclerosis, metabolic, dyslipidemia, LDL-C

\section{Introduction}

Second generation antipsychotics (SGAs) are the most prescribed drugs in the treatment of schizophrenia worldwide. ${ }^{1}$ SGAs are superior to conventional antipsychotics in having lower risk for extrapyramidal symptoms, and they have better antipsychotic effects. ${ }^{2}$ Although SGAs have many benefits and may reduce some of the factors related to the morbidity and mortality of schizophrenia, these drugs appear to be associated with varying degrees of metabolic adverse effects, such as weight gain, impaired glucose metabolism, dyslipidemia and, in some cases, more serious morbidity, such as cardiovascular disease. ${ }^{3}$
Correspondence: Yakup Albayrak Namik Kemal University, School of Medicine, Department of Psychiatry, Tunca Caddesi, Tekirdağ, 59100, Turkey Tel +905056355434

Fax +90282 2509950

Email dr.fuge@hotmail.com submit your manuscript | www.dovepress.com

Dovepress

http://dx.doi.org/1 0.2147/NDT.S52463 
While most clinical studies on SGA side effects have focused on weight gain and glucose intolerance, the importance of recognizing and treating hyperlipidemia in schizophrenia patients cannot be overestimated because of the effects of untreated hyperlipidemia. ${ }^{4,5}$ For patients suffering from schizophrenia, failure to detect lipid abnormalities is greater compared with the general population because of the limited access to general medical services and routine preventive care seen in chronically mentally ill patients., Most studies that have investigated dyslipidemia in patients who take SGAs have focused on the effect of serum lipids on weight gain. ${ }^{5}$ Several studies have reported the possible association between the lifestyle and dietary patterns of patients with schizophrenia and dyslipidemia. ${ }^{7,8}$ However, the exact mechanism of dyslipidemia during treatment with SGAs still remains unclear.

Paraoxonases were originally discovered as enzymes that hydrolyze exogenous toxic organophosphate compounds, such as the insecticide paraoxon. Three members of the paraoxonase family are currently known: paraoxonase 1 (PON1), PON2, and PON3, which are encoded by three separate genes on the same chromosome (7 in human, 6 in mouse). PON1 protein consists of 354 amino acids with molecular mass $45 \mathrm{kDa} .{ }^{9}$ After the introduction of the oxidative stress hypothesis of atherosclerosis and the discovery of the antioxidant effect of high-density lipoprotein cholesterol (HDL-C), ${ }^{10,11}$ PON1 attracted significant interest as a protein that is responsible for most of the antioxidant properties of HDL-C. The exact antioxidant mechanism of PON1 is not yet known, although it is known that its protective effect does not stem from chelating of copper ions or because of potential lipid transfer from low-density lipoprotein cholesterol (LDL-C) to HDL-C. The existence of an enzymatic mechanism is supported by the observation that heat inactivation of purified PON1 abolishes its antioxidant effect. ${ }^{12}$ Furthermore, growing evidence supports atheroprotective effects of PON1 activity. ${ }^{13,14}$

Olanzapine and quetiapine are well-established SGAs for the treatment of schizophrenia. Although olanzapine and quetiapine have similar chemical structures and both of them are classified as dibenzodiazepines, accumulating evidence suggests that they have different effects on metabolic parameters, such as fasting glucose, weight gain, and serum lipid levels. ${ }^{15}$ In the present study, we aimed to determine serum PON1 activity in patients with schizophrenia who have been treated with either olanzapine or quetiapine and in age- and sex-matched healthy subjects.

\section{Materials and methods}

\section{Subjects}

This was a cross-sectional study. One hundred and ten outpatients who had been treated with either olanzapine or quetiapine were preliminarily recruited in Kirklareli State Hospital between May 2012 and May 2013 among patients with a diagnosis of schizophrenia according to the Diagnostic and Statistical Manual of Mental Disorders (DSM-IV), Text Revision. ${ }^{16}$ The diagnoses were made and confirmed by a trained psychiatrist using the Structured Clinical Interview for DSM-IV Axis I Disorders. ${ }^{17,18}$ The patients were recruited from inpatient service, outpatient service, and community health service. All of the patients were receiving treatment with either olanzapine or quetiapine for at least 1 year. The inclusion criteria were 1) aged between 18-65 years and 2) undergoing treatment with either olanzapine or quetiapine. The exclusion criteria were a history of any alcohol or drug dependence; any past or present major medical or neurological illness; undergoing any additional drug treatment that might alter serum lipid profile or serum PON1 activity; taking any additional psychotropic drugs except benzodiazepines; having a body mass index (BMI) $\geq 30 \mathrm{~kg} / \mathrm{m}^{2}$; and any additional psychiatric disorder or mental retardation. From the initial sample of 110 patients, 25 were excluded because their BMI was greater than $30 \mathrm{~kg} / \mathrm{m}^{2} ; 18$ were excluded because they had been taking mood stabilizers, long-acting antipsychotics, first-generation antipsychotics, or SGAs besides olanzapine or quetiapine; and three were excluded because of mental retardation. Therefore, 64 patients with schizophrenia were included in the final sample. Additionally, 32 healthy controls (HCs) matched for age, sex, and smoking status were included, all with BMI $\leq 30 \mathrm{~kg} / \mathrm{m}^{2}$. All patients and healthy subjects lived in Kirklareli (west part of Turkey), and all of them habitually followed the traditional Mediterranean diet, rich in vegetables, fish, and lamb. The study was approved by our local ethics committee. All of the patients were adequately competent to provide written informed consent, which was obtained from all patients and their families after a full explanation of the procedures of the study. All HCs agreed to participate in the study and provided informed consent.

\section{Psychopathological assessment of patients}

Structured Clinical Interview for DSM-IV

Axis I (SCID-I)

SCID-I is a semistructured interview for making the major DSM-IV Axis I diagnoses. The instrument is designed 
to be administered by a clinician or trained mental health professional. It was developed by First et al, ${ }^{18}$ and the Turkish version of SCID-I was validated by Corapcioglu et al. ${ }^{17}$

\section{Biochemical procedures}

Blood samples were collected from patients (Preanalytic Systems; BD, Franklin Lakes, NJ, USA) at 8-9 am after 8-12 hours of fasting. Professional staff performed venipuncture, using vacutainers to obtain $10 \mathrm{~mL}$ of whole blood. The samples were centrifuged at 3,500 rpm for 5 minutes, and serum samples were kept at $-20^{\circ} \mathrm{C}$ until assayed. Serum total cholesterol (TC), triglyceride (TG), HDL-C, and LDL-C were measured by an Olympus AU 600 autoanalyzer (Olympus Corporation, Tokyo, Japan) using commercially available assay kits. Serum TC, TG, HDL-C, and LDL-C were measured the same day that the blood was collected. The analysis was made by a technician, who was blinded to the diagnostic status of the subjects. The identity of all subjects was indicated by a code number maintained by the investigator until all biochemical analyses were completed.

PON1 activity was determined by using paraoxon as a substrate and measured by increases in the absorbance of visible light at $412 \mathrm{~nm}$ due to the formation of 4-nitrophenol, as previously described. ${ }^{19,20}$ Briefly, PON1 activity was measured at $25^{\circ} \mathrm{C}$ by adding $50 \mu \mathrm{L}$ of serum to $1 \mathrm{~mL}$ Tris$\mathrm{HCl}$ buffer (100 $\mathrm{mM}$ at $\mathrm{pH} 8.0$ ) containing $2 \mathrm{mM}$ of $\mathrm{CaCl}_{2}$ and $5.5 \mathrm{mM}$ of paraoxon. The rate of generation of 4-nitrophenol was determined at wavelength $412 \mathrm{~nm}$. Enzymatic activity was calculated using the molar extinction coefficient $17,100 \mathrm{M}^{-1} \mathrm{~cm}^{-1}$. The intra- and interassay coefficients of variation for PON1 activity were $<3 \%$. The results are expressed as units per liter, in which $1 \mathrm{U} / \mathrm{L}$ is equal to the hydrolysis of $1 \mu \mathrm{mol}$ substrate per minute in 1 liter.

The total antioxidant potential (TAOP) of serum was determined using a novel automated measurement method developed by Erel. ${ }^{21}$ In this method, the hydroxyl radical, which is the most potent biological radical, is produced. In the assay, ferrous ion solution, which is present in reagent 1 , is mixed with hydrogen peroxide $\left(\mathrm{H}_{2} \mathrm{O}_{2}\right)$, which is present in reagent 2 . The resulting products of this reaction, such as brown-colored dianisidinyl radical cation, produced by the hydroxyl radical, are also potent radicals. Using this method, the antioxidative effect of the sample against the potent free radical reaction is measured. The assay has been found to have excellent precision: $<3 \%$. The results are expressed as mmol trolox equivalent/L. Similarly, total peroxide levels (TPEROX) of serum were determined using a novel automated measurement method, developed by Erel. ${ }^{22}$ Oxidants present in the sample oxidize the ferrous ion-o-dianisidine complex to ferric ion. The oxidation reaction is enhanced by glycerol molecules, which are abundant in the reaction medium. The ferric ion makes a colored complex with xylenol orange in an acidic medium. The color intensity, which can be measured spectrophotometrically, is related to the total amount of oxidant molecules present in the sample. The assay is calibrated with $\mathrm{H}_{2} \mathrm{O}_{2}$ and the results are expressed in terms of micromolar $\mathrm{H}_{2} \mathrm{O}_{2}$ equivalent per liter (mmol $\mathrm{H}_{2} \mathrm{O}_{2}$ equivalent/L). The ratio of TPEROX to TAOP is referred to as the oxidative stress index (OSI). The OSI is calculated according to the following formula: ${ }^{22}$

OSI arbitrary unit $=\frac{\text { TPEROX mmol } \mathrm{H}_{2} \mathrm{O}_{2} \text { equivalent } / \mathrm{L}}{\text { TAOP mmol trolox equivalent } / \mathrm{L}}$

\section{Statistical methods}

Data were analyzed using the Statistical Package for the Social Sciences for Windows, version 16.0 (SPSS; IBM Corporation, Armonk, NY, USA). A confidence interval of $95 \%$ and a two-tailed $P$-value of less than 0.05 were considered to be statistically significant for all analyses. Variables were tested for homogeneity of variance using the Levene's test, and for normality of distribution by utilizing the Kolmogorov-Smirnov test. Differences between serum levels of TAOP, TPEROX, LDL-C, TG, and status of OSI were tested with a series of one-way analyses of variance. Tukey's honestly significant difference test was applied in post hoc analysis for the multiple comparisons of three groups. The results are expressed as the mean \pm standard deviation. Because the distribution of the serum levels of PON1, TC, HDL-C, TG, and age were not homogeneous, the differences between these five parameters were assessed by the Kruskal-Wallis nonparametric test. The post hoc analysis of variables that were found to be significant after the Kruskal-Wallis nonparametric test were assessed by the Mann-Whitney $U$ test. The nonparametric numerical data are presented as median, minimum, and maximum values. Differences in sex, smoking status, and place of residence were assessed by a $\chi^{2}$ test. Pearson correlation was performed to analyze the correlation between parametric variables, while nonparametric variables were analyzed by Spearman analysis.

\section{Results \\ Sociodemographic and clinical characteristics}

Thirty-five patients had been treated with olanzapine, and 29 patients had been treated with quetiapine. The mean daily 
doses of olanzapine and quetiapine were $13.28 \pm 5.13 \mathrm{mg} /$ day and $513.79 \pm 130.17 \mathrm{mg} /$ day, respectively. While the daily doses converted to chlorpromazine-equivalent doses, the daily doses in olanzapine and quetiapine were $265.71 \pm 87.26 \mathrm{mg}$ and $683.91 \pm 155.48 \mathrm{mg}$, respectively, and the dose was found to be significantly higher in the quetiapine group $(t=-13.56, P<0.001)$. The median ages (range) of the olanzapine, quetiapine, and HC groups were, respectively, 38 years (22-55), 42 years (20-58), and 35 years $(28-45)$, which were no different $(d f=2$, $P=0.078$ ). The groups were also similar in terms of sex and smoking status $\left(\chi^{2}=3.71, P=0.156\right.$ and $\chi^{2}=0.91, P=0.61$, respectively). The BMIs of the olanzapine, quetiapine, and HC groups were $23.44 \pm 1.67 \mathrm{~kg} / \mathrm{m}^{2}, 23.41 \pm 0.68 \mathrm{~kg} / \mathrm{m}^{2}$, and $23.21 \pm 0.77 \mathrm{~kg} / \mathrm{m}^{2}$, respectively, and the groups were similar to each other $(F=0.92, P=0.4)$. The durations of treatment in olanzapine and quetiapine groups were $6.02 \pm 2.58$ years and $6.27 \pm 2.77$ years, respectively, and the groups were similar to each other in terms of duration of treatment $(t=-0.36, P=0.71)$ (Table 1).

The median values of serum TC in the olanzapine, quetiapine, and HC groups were $194 \mathrm{mg} / \mathrm{dL}, 172.5 \mathrm{mg} /$ $\mathrm{dL}$, and $188.5 \mathrm{mg} / \mathrm{dL}$, respectively ( $d f=2, P=0.042)$. The median value of TC in the olanzapine group was significantly higher than in the quetiapine and HC groups $(z=-1.91$, $P=0.05$ and $z=-2.33, P=0.02$, respectively). The mean values of serum LDL-C in the olanzapine, quetiapine, and HC groups were $129.4 \pm 34.44 \mathrm{mg} / \mathrm{dL}, 108 \pm 29.19 \mathrm{mg} / \mathrm{dL}$, and $110.78 \pm 30.59 \mathrm{mg} / \mathrm{dL}$, respectively $(F=8.92, P=0.038)$. The mean value of serum LDL-C in the olanzapine group was significantly higher than the quetiapine and HC groups ( $P=0.03$ and $P=0.04$, respectively). The median values of serum TG and HDL-C were similar between groups (TG: $d f=2, P=0.88$; HDL-C: $d f=2, P=0.472$ ) (Table 1).

\section{Serum PONI activity, serum TAOP and TPEROX levels, and status of OSI in the olanzapine, quetiapine, and $\mathrm{HC}$ groups}

The median (range) values of PON1 activity in the olanzapine, quetiapine, and HC groups were 93 U/L (42-294), $156 \mathrm{U} / \mathrm{L}$ (40-529), and 156.5 U/L (56-520), respectively. There was a significant difference between groups $(d f=2$, $P=0.008$ ). The median value of serum PON1 activity in the olanzapine group was significantly lower than the quetiapine group $(z=-2.45, P=0.014)$ and HC group $(z=-2.89$, $P=0.04$ ) (Table 1). PON1 activity was similar between the quetiapine and $\mathrm{HC}$ groups $(z=-0.87, P=0.91)$. The median values of serum PON1 in the HC group and the combined group of olanzapine and quetiapine groups were $156 \mathrm{U} / \mathrm{L}(56-520)$ and $100 \mathrm{U} / \mathrm{L}$ (40-529), respectively, and there was no significant difference between groups

Table I Sociodemographic and clinical characteristics of participants

\begin{tabular}{|c|c|c|c|c|}
\hline & $\begin{array}{l}\text { Olz } \\
(n=35)\end{array}$ & $\begin{array}{l}\text { Quet } \\
(n=29)\end{array}$ & $\begin{array}{l}\mathrm{HC} \\
(n=32)\end{array}$ & Statistics \\
\hline Age (years) & $38(22-55)$ & $42(20-58)$ & $35(28-45)$ & $d f=2, P=0.078$ \\
\hline \multicolumn{5}{|l|}{ Sex } \\
\hline Female & 20 (57.I\%) & 15 (51.7\%) & II(34.4\%) & \multirow[t]{2}{*}{$\chi^{2}=3.71, P=0.156$} \\
\hline Male & 15 (42.9\%) & 14 (48.3\%) & 21 (65.6\%) & \\
\hline \multicolumn{5}{|l|}{ Smoking } \\
\hline Yes & I8 (51.4\%) & $12(41.4 \%)$ & $17(53.1 \%)$ & \multirow[t]{2}{*}{$\chi^{2}=0.91, P=0.61$} \\
\hline No & 17 (48.6\%) & $17(58.6 \%)$ & 15 (46.9\%) & \\
\hline \multirow[t]{4}{*}{ TC (mg/dL) } & \multirow[t]{4}{*}{$194(142-293)$} & \multirow[t]{4}{*}{$172.5(102-235)$} & \multirow[t]{4}{*}{$188.5(103-220)$} & $d f=2, P=0.042$ \\
\hline & & & & Olz and Quet: $\mathbf{P}=\mathbf{0 . 0 4}$ \\
\hline & & & & Olz and HC: $\mathbf{P}=\mathbf{0 . 0 2}$ \\
\hline & & & & Quet and HC: $P=0.7 \mathrm{I}$ \\
\hline TG (mg/dL) & I 66.7 (48-389) & I6I.I (42-298) & 159.3 (89-242) & $d f=2, P=0.88$ \\
\hline \multirow[t]{4}{*}{ LDL-C (mg/dL) } & \multirow[t]{4}{*}{$129.4 \pm 34.44$} & \multirow[t]{4}{*}{$108 \pm 29.19$} & \multirow[t]{4}{*}{$110.78 \pm 30.59$} & $F=8.92, P=0.038$ \\
\hline & & & & Olz and Quet: $\mathbf{P}=\mathbf{0 . 0 3}$ \\
\hline & & & & Olz and HC: $P=0.04$ \\
\hline & & & & Quet and HC: $P=0.8 \mathrm{I}$ \\
\hline HDL-C (mg/dL) & $36(24-57)$ & $39.5(30-5 I)$ & $40(27-56)$ & $d f=2, P=0.472$ \\
\hline BMI $\left(\mathrm{kg} / \mathrm{m}^{2}\right)$ & $23.44 \pm 1.67$ & $23.41 \pm 0.68$ & $23.21 \pm 0.77$ & $F=0.92, P=0.4$ \\
\hline Daily dose $(\mathrm{mg})^{*}$ & $265.71 \pm 87.26$ & $683.91 \pm 155.48$ & - & $t=-13.56, \mathbf{P}<\mathbf{0 . 0 1}$ \\
\hline
\end{tabular}

Notes: *Represents chlorpromazine-equivalent dose. Significant differences between groups are highlighted in bold. Age, TC, and HDL-C are represented as median (range); TG, LDL-C, BMI, and Daily dose are represented as mean \pm standard deviation.

Abbreviations: BMI, body mass index; HC, healthy control; HDL-C, high-density lipoprotein cholesterol; LDL-C, low-density lipoprotein cholesterol; Olz, olanzapine group; Quet, quetiapine group; TC, total cholesterol; TG, triglyceride. 
( $z=-1.15, P=0.11$ ). Plasma TAOP levels of olanzapine, quetiapine, and $\mathrm{HC}$ groups were $1.95 \pm 0.23 \mathrm{mmol}$ trolox equivalent/L, $2.05 \pm 0.33 \mathrm{mmol}$ trolox equivalent/L, and $2.06 \pm 0.29 \mathrm{mmol}$ trolox equivalent $/ \mathrm{L}$, respectively, and there was no significant difference between groups $(F=1.57$, $P=0.21$ ). Plasma TPEROX levels of olanzapine, quetiapine, and $\mathrm{HC}$ groups were $6.51 \pm 2.11 \mathrm{mmol}_{2} \mathrm{O}_{2}$ equivalent/L, $6.93 \pm 3.7 \mathrm{mmol} \mathrm{H}_{2} \mathrm{O}_{2}$ equivalent/L, and $6.57 \pm 2.29 \mathrm{mmol}$ $\mathrm{H}_{2} \mathrm{O}_{2}$ equivalent/L, respectively. There was no significant difference between groups $(F=0.20, P=0.81)$. OSI values of olanzapine, quetiapine, and $\mathrm{HC}$ groups were respectively, $0.34 \pm 0.11$ (TPEROX mmol $\mathrm{H}_{2} \mathrm{O}_{2}$ equivalent/L)/(TAOP mmol trolox equivalent/L), $0.33 \pm 0.14$ (TPEROX mmol $\mathrm{H}_{2} \mathrm{O}_{2}$ equivalent/L)/(TAOP mmol trolox equivalent/L), and $0.32 \pm 0.11$ (TPEROX mmol $\mathrm{H}_{2} \mathrm{O}_{2}$ equivalent/L)/(TAOP mmol trolox equivalent/L). There was a significant difference between groups $(F=0.12, P=0.88)$ (Table 2$)$.

\section{Correlations of serum PONI activity with clinical variables in the olanzapine, quetiapine, and $\mathrm{HC}$ groups}

In the olanzapine group, there was a positive correlation ( $r=0.342, P=0.045$ ) between serum PON1 activity and serum HDL-C level. There were no significant correlations between serum PON1 activity and TC, LDL-C, TG, age, sex, or smoking status. In the quetiapine and $\mathrm{HC}$ groups, there were no significant correlations between serum PON1 activity and TC, LDL-C, HDL-C, TG, age, sex, or smoking status. While all participants were assessed together, there were no significant correlations between serum PON1 activity and TC, LDL-C, HDL-C, TG, age, sex, or smoking status (Table 3 ).

\section{Discussion}

The major findings of the present study are that serum PON1 activity in patients with schizophrenia, who had been treated with olanzapine, was significantly lower than that of patients treated with quetiapine and $\mathrm{HCs}$, and that there was a positive correlation between serum PON1 activity and HDL-C level in the olanzapine group.

Cardiovascular diseases are the most important causes of mortality and morbidity in Western countries despite the development of new medications, new approaches, and new technologies, such as stents and increased awareness of cardiovascular risk factors. ${ }^{4}$ Hypertension, hyperlipidemia, diabetes mellitus, and smoking are traditional risk factors for coronary artery disease. Diabetes mellitus and smoking are more prevalent in patients with schizophrenia compared with the general population. ${ }^{23}$ The mortality rate caused by cardiovascular diseases in schizophrenics is two-fold the rate in the nonschizophrenic population in large epidemiologic studies. ${ }^{24}$ Dyslipidemia is a familiar metabolic side effect of atypical antipsychotics. Dyslipidemia is common during atypical antipsychotic treatment. ${ }^{5}$ Olanzapine use is associated with dyslipidemia, including increased serum $\mathrm{TG}^{25-37}$ increased TC, ${ }^{30,35-40}$ increased serum LDL-C, ${ }^{35-37,39-41}$ and decreased serum HDL-C. ${ }^{42,43}$ Unlike clozapine and olanzapine, quetiapine generally has a much lower propensity to cause weight gain. ${ }^{44}$ Nonetheless, the data suggest that quetiapine shares the propensity with other benzodiazepine-derived atypical antipsychotics to primarily elevate serum TG. ${ }^{26,27,45-47}$ Clozapine, olanzapine, and to a lesser extent, quetiapine are associated with elevations in TG and TC, whereas risperidone and aripiprazole have minimal or no effect on these lipid parameters. ${ }^{48}$

Table 2 Serum PONI activity, serum TAOP and TPEROX levels, and status of OSI in the olanzapine, quetiapine, and HC groups

\begin{tabular}{|c|c|c|c|c|}
\hline & $\begin{array}{l}\mathrm{Olz} \\
(n=35)\end{array}$ & $\begin{array}{l}\text { Quet } \\
(n=29)\end{array}$ & $\begin{array}{l}\mathrm{HC} \\
(n=32)\end{array}$ & Statistics \\
\hline PONI (U/L) & $93(42-294)$ & I $56(40-529)$ & I56.5 (56-520) & $\begin{array}{l}d f=2, P=0.008 \\
\text { Olz and Quet: } P=0.01 \\
\text { Olz and HC: } P=0.04 \\
\text { Quet and } H C: P=0.91\end{array}$ \\
\hline $\begin{array}{l}\text { TAOP } \\
\text { (mmol trolox equivalent/L) }\end{array}$ & $1.95 \pm 0.23$ & $2.05 \pm 0.33$ & $2.06 \pm 0.29$ & $F=\mid .57, P=0.21$ \\
\hline $\begin{array}{l}\text { TPEROX } \\
\left(\text { mmol } \mathrm{H}_{2} \mathrm{O}_{2} \text { equivalent/L) }\right.\end{array}$ & $6.51 \pm 2.11$ & $6.93 \pm 3.7$ & $6.57 \pm 2.29$ & $F=0.20, P=0.81$ \\
\hline $\begin{array}{l}\text { OSI } \\
\text { (TPEROX mmol } \mathrm{H}_{2} \mathrm{O}_{2} \text { equivalent/L)/ } \\
\text { (TAOP mmol trolox equivalent/L) }\end{array}$ & $0.34 \pm 0.11$ & $0.33 \pm 0.14$ & $0.32 \pm 0.11$ & $F=0.12, P=0.88$ \\
\hline
\end{tabular}

Notes: Significant difference between groups is highlighted in bold. PONI is presented as median (range); TAOP, TPREOX, and OSI are presented as mean \pm standard deviation.

Abbreviations: $\mathrm{H}_{2} \mathrm{O}_{2}$, hydrogen peroxide; $\mathrm{HC}$, healthy control; Olz, olanzapine group; OSI, oxidative stress index; PONI, paraoxonase I; Quet, quetiapine group; TAOP, total antioxidant potentials; TPEROX, total peroxide level. 
Table 3 Correlation coefficients between scores of PONI and age, sex, TC, TG, LDL-C, HDL-C, and smoking status in olanzapine, quetiapine, and $\mathrm{HC}$ groups

\begin{tabular}{llllllll}
\hline PON I & Age & Sex & TC & TG & LDL-C & HDL-C & Smoking \\
\hline Olz & -0.199 & -0.132 & 0.24 & -0.088 & -0.129 & $\mathbf{0 . 3 4 2}$ & 0.178 \\
Quet & 0.294 & -0.04 & 0.178 & 0.099 & -0.163 & 0.207 & -0.201 \\
HC & 0.043 & 0.082 & 0.122 & -0.106 & -0.085 & -0.034 & -0.058
\end{tabular}

Note: Significant $P$-values predicted in bold.

Abbreviations: HC, healthy control; HDL-C, high-density lipoprotein cholesterol; LDL-C, low-density lipoprotein cholesterol; Olz, olanzapine group; PONI, paraoxonase I; Quet, quetiapine group; TC, total cholesterol; TG, triglyceride.

While major changes in serum lipid levels are side effects of some medications, main agents are considered to have specific effects on particular lipid fractions. Isotretinoin, acitretin, certain protease inhibitors, low-potency phenothiazines, and dibenzodiazepine-derived antipsychotics primarily elevate serum TG.$^{49}$ There are several possible mechanisms for the described drug-induced dyslipidemia. For most agents associated with lipid dysregulation, these mechanisms are unclear, and that remains the case for antipsychotic-induced hyperlipidemia. However, several biologically plausible hypotheses have cited weight gain, dietary changes, and the development of glucose intolerance to explain the high incidence of hyperlipidemia with certain antipsychotic medications. ${ }^{5,46}$ Weight gain and obesity increase the risk of hyperlipidemia, and the use of SGAs is frequently associated with a considerable increase in body weight. ${ }^{50}$ This variability in the propensity to induce weight gain is quite marked among the SGAs, ${ }^{50}$ with clozapine and olanzapine and possibly zotepine associated with the greatest gains in weight. ${ }^{44}$ Obesity and weight gain have a demonstrable negative impact on serum lipid profiles, so it is not surprising that those SGAs most likely to cause significant weight gain are also correlated with the greatest impact on serum lipids. While the mechanisms mentioned above are plausible for changes in serum TG during antipsychotic treatment, they are insufficient to explain the changes in serum LDL-C during treatment with SGAs. In our study, serum PON1 activity in the olanzapine group was significantly lower than that of the quetiapine group and HCs. Furthermore, serum LDL-C in the olanzapine group was higher than in the quetiapine group and $\mathrm{HCs}$, and none of the participants were obese. Considering the potential role of PON1 in lipid transfer from LDL-C to HDL-C, it is likely that decreased serum PON1 activity is associated with the increased LDL-C in the olanzapine group. Interestingly, serum PON-1 activity is reported to be negatively correlated with serum LDL-C level..$^{51,52}$ Furthermore, our finding of a positive correlation between serum PON1 activity and HDL-C level in the olanzapine group is of great interest. Because the groups did not have any comorbid medical illness, and we attempted to exclude the factors that might possibly alter serum PON1 activity, and there were evidences that explored the association between serum PON1 activity and serum HDL-C levels, we suggest that there might be an indirect relationship between serum HDL-C level and olanzapine use which might be effected from serum PON1 activity.

There is growing evidence that PON1 activity provides atheroprotective effects. ${ }^{13}$ Experimental animal studies have revealed increased plasma oxidized phospholipids in lowdensity lipoproteins and intermediate density lipoproteins, increased rates of low-density lipoprotein oxidation and clearance, increased adhesion of leukocytes, faster development of atherosclerotic lesions, increased superoxide generation in the aortic wall, and shorter time of thrombotic occlusion in PON1-knockout mice. ${ }^{14}$ Moreover, PON1-overexpressing mice have enhanced protection of HDL-C and LDL-C from oxidation, improved oxidation status of the aorta and peritoneal macrophages, and decreased lesion size. ${ }^{14}$ A 2012 metaanalysis of 47 studies with 9,853 patients with coronary artery disease and 11,408 control subjects confirmed the association of lower plasma PON1 activity with increased coronary artery disease risk (19\% lower PON1 activity, $P<0.00001) .{ }^{53}$ Another recent meta-analysis that included 43 studies with a total 20,629 subjects showed a similar association between PON1 activity and coronary artery disease, with a standardized mean difference of $-0.78(P<0.001)$ for coronary artery disease subjects compared with controls. ${ }^{54}$ These two meta analyses demonstrated increased risk of coronary artery disease in subjects with lower PON1 activity, regardless of age and ethnicity. Furthermore, some agents such as fibrates and statins affect serum PON1 activity. ${ }^{14}$ In our study, patients who had been treated with olanzapine had reduced serum PON1 activity compared with patients who had been treated with quetiapine and the HCs. Considering the increased rates of cardiovascular diseases in patients with schizophrenia compared with the normal population, these findings are noteworthy. To our knowledge, this is the first study to compare the effects of olanzapine and quetiapine on serum 
PON1 activity. Furthermore the chlorpromazine-equivalent dose was significantly higher in the quetiapine group; thus we suggest that the inhibitor effect of olanzapine on serum PON1 activity might not be dose-dependent. We suggest that after this preliminary study and possible future studies that confirm our results, patients who receive olanzapine treatment should be followed-up more carefully in terms of cardiovascular diseases, and if cardiovascular risk factors appear during treatment (eg, dyslipidemia, obesity), the treatment should be revised according to the patient's status.

Although we attempted to eliminate some confounding factors, such as obesity and metabolic diseases, our study has some limitations. First, we could only include patients under treatment with olanzapine and quetiapine. Multicenter studies using a large sample size and a prospective manner are needed to explore and compare the effects of each SGA on serum PON1 activity. Second, all patients enrolled in this study were medicated. Therefore, further studies using first-episode, drug-naïve patients with schizophrenia will be necessary. Other limitations to the present study are that we included all patients who were eligible, thus we could not calculate sample size estimation, and we also could not give information about exercise habits of the participants.

\section{Conclusion}

To our knowledge, this study is the first to demonstrate reduced serum PON1 activity in schizophrenic patients who were being treated with olanzapine but not quetiapine. Further studies using a large sample size are needed to investigate serum PON1 activity and its relationship with cardiovascular and metabolic side effects during treatment with SGAs.

\section{Author contributions}

Authors Cüneyt Ünsal, Yakup Albayrak, and Neslihan Albayrak designed the study and wrote the protocol. Authors Murat Kuloğlu and Kenji Hashimoto managed the literature searches and analyses. Authors Cüneyt Ünsal and Yakup Albayrak undertook the statistical analysis, and wrote the first draft of the manuscript. All authors contributed to the critical revision of the manuscript and have approved the final proof to be published.

\section{Disclosure}

The authors report no conflicts of interest in this work.

\section{References}

1. Meltzer HY. Update on typical and atypical antipsychotic drugs. Annu Rev Med. 2013;64:393-406.
2. Haro JM, Salvador-Carulla L. The SOHO (Schizophrenia Outpatient Health Outcome) study: implications for the treatment of schizophrenia. CNS Drugs. 2006;20(4):293-301.

3. Newcomer JW. Metabolic considerations in the use of antipsychotic medications: a review of recent evidence. J Clin Psychiatry. 2007; 68(Suppl 1):20-27.

4. Executive Summary of The Third Report of The National Cholesterol Education Program (NCEP) Expert Panel on Detection, Evaluation, And Treatment of High Blood Cholesterol In Adults (Adult Treatment Panel III). JAMA. 2001;285(19):2486-2497.

5. Meyer JM, Koro CE. The effects of antipsychotic therapy on serum lipids: a comprehensive review. Schizophr Res. 2004;70(1):1-17.

6. Meyer JM. Cardiovascular illness and hyperlipidemia in patients with schizophrenia. In: Meyer JM, Nasrallah HA, editors. Medical Illness and Schizophrenia. Washington, DC: American Psychiatric Publishing; 2003:50-83.

7. Le Fevre PD. Improving the physical health of patients with schizophrenia: therapeutic nihilism or realism? Scott Med J. 2001;46(1):11-13.

8. Jenkins DJ, Kendall CW, Marchie A, et al. Effects of a dietary portfolio of cholesterol-lowering foods vs lovastatin on serum lipids and C-reactive protein. JAMA. 2003;290(4):502-510.

9. Primo-Parmo SL, Sorenson RC, Teiber J, La Du BN. The human serum paraoxonase/arylesterase gene (PON1) is one member of a multigene family. Genomics. 1996;33(3):498-507.

10. Gan KN, Smolen A, Eckerson HW, and La Du BN. Purification of human serum paraoxonase/arylesterase. Evidence for one esterase catalyzing both activities. Drug Metab Dispos. 1991;19(1):100-106.

11. Osaki F, Ikeda Y, Suehiro T, et al. Roles of Sp1 and protein kinase C in regulation of human serum paraoxonase 1 (PON1) gene transcription in HepG2 cells. Atherosclerosis. 2004;176(2):279-287.

12. Brophy VH, Jampsa RL, Clendenning JB, McKinstry LA, Jarvik GP, Furlong CE. Effects of 5' regulatory-region polymorphisms on paraoxonase-gene (PON1) expression. Am J Hum Genet. 2001;68(6): $1428-1436$.

13. Schrader C, Rimbach G. Determinants of paraoxonase 1 status: genes, drugs and nutrition. Curr Med Chem. 2011;18(36):5624-5643.

14. Litvinov D, Mahini H, Garelnabi M. Antioxidant and anti-inflammatory role of paraoxonase 1: implication in arteriosclerosis diseases. $N \mathrm{Am}$ J Med Sci. 2012;4(11):523-532.

15. Nasrallah HA. Atypical antipsychotic-induced metabolic side effects: insights from receptor-binding profiles. Mol Psychiatry. 2008; 13(1):27-35.

16. American Psychiatric Association, editor. Diagnostic and Statistical Manual of Mental Disorders. 4th ed. Washington, DC: American Psychiatric Publishing; 2000.

17. Corapcioglu A, Aydemir O, Yildiz M. DSM-IV Structured Clinical Interview for DSM-IV (SCID-IV), Turkish Version (Turkish). Ankara, Turkey: Hekimler Yayin Birligi; 1999.

18. First MB, Spitzer RL, Gibbon M, Williams JBW. Structured Clinical Interview for DSM-IV Axis I Disorders, Clinician Version (SCID-CV). Washington, DC: American Psychiatric Publishing; 1996.

19. Camps J, Marsillach J, Joven J. The paraoxonases: role in human diseases and methodological difficulties in measurement. Crit Rev Clin Lab Sci. 2009;46(2):83-106.

20. Isik A, Koca SS, Ustundag B, Celik H, Yildirim A. Paraoxonase and arylesterase levels in rheumatoid arthritis. Clin Rheumatol. 2007;26(3): 342-348.

21. Erel O. A novel automated method to measure total antioxidant response against potent free radical reactions. Clin Biochem. 2004;37:112-119.

22. Erel O. A new automated colorimetric method for measuring total oxidant status. Clin Biochem. 2005;38(12):1103-1111.

23. Davidson M. Can premorbid and prodromal markers associated with psychosis be utilized for early detection and secondary prevention of schizophrenia? Dialogues Clin Neurosci. 2001;3(2):138-143.

24. Osby U, Correia N, Brandt L, Ekbom A, Sparén P. Mortality and causes of death in schizophrenia in Stockholm county, Sweden. Schizophr Res. 2000;45(1-2):21-28. 
25. Bouchard RH, Demers MF, Simoneau I, et al. Atypical antipsychotics and cardiovascular risk in schizophrenic patients. $J$ Clin Psychopharmacol. 2001;21(1):110-111.

26. Atmaca M, Kuloglu M, Tezcan, Gecici O. Ustundag B. Weight gain, serum leptin and triglyceride levels in patients with schizophrenia on antipsychotic treatment with quetiapine, olanzapine and haloperidol. Schizophr Res. 2003;60(1):99-100.

27. Atmaca M, Kuloglu M, Tezcan E, Ustundag B. Serum leptin and triglyceride levels in patients on treatment with atypical antipsychotics. J Clin Psychiatry. 2003;64(5):598-604.

28. Wirshing DA, Boyd JA, Meng LR, Ballon JS, Marder SR, Wirshing WC. The effects of novel antipsychotics on glucose and lipid levels. $J$ Clin Psychiatry. 2002;63(10):856-865.

29. Meyer JM. A retrospective comparison of weight, lipid, and glucose changes between risperidone- and olanzapine-treated inpatients: metabolic outcomes after 1 year. J Clin Psychiatry. 2002;63(5): $425-433$.

30. Koro CE, Fedder DO, L'Italien GJ, et al. An assessment of the independent effects of olanzapine and risperidone exposure on the risk of hyperlipidemia in schizophrenic patients. Arch Gen Psychiatry. 2002;59(11):1021-1026.

31. Nasrallah HA, Perry CL, Love E, Nasrallah AT. Are there ethnic differences in hypertriglyceridemia secondary to olanzapine treatment. Poster presented at 40th Annual Meeting of the American College of Neuropsychopharmacology; December 10, 2001; Waikoloa, Hawaii.

32. Meyer JM. Effects of atypical antipsychotics on weight and serum lipid levels. J Clin Psychiatry. 2001;62(Suppl 27):27-34.

33. Sheitman BB, Bird PM, Binz W, Akinli L, Sanchez C. Olanzapineinduced elevation of plasma triglyceride levels. Am J Psychiatry. 1999;156(9):1471-1472.

34. Osser DN, Najarian DM, Dufresne RL. Olanzapine increases weight and serum triglyceride levels. J Clin Psychiatry. 1999;60(11):767-770.

35. Kryzhanovskaya LA, Xu W, Millen BA, Acharya N, Jen KY, Osuntokun O. Comparison of long-term (at least 24 weeks) weight gain and metabolic changes between adolescents and adults treated with olanzapine. J Child Adolesc Psychopharmacol. 2012;22(2):157-165.

36. Kaushal J, Bhutani G, Gupta R. Comparison of fasting blood sugar and serum lipid profile changes after treatment with atypical antipsychotics olanzapine and risperidone. Singapore Med J. 2012;53(7):488-492.

37. Shao P, Ou J, Wu R, et al. [Effects of ziprasidone and olanzapine on glucose and lipid metabolism in first-episode schizophrenia]. Zhong Nan Da Xue Xиe Bao Yi Xue Ban. 2013;38(4):365-369. Chinese.

38. Goodnick PJ, Jerry JM. Aripiprazole: profile on efficacy and safety. Expert Opin Pharmacother. 2002;3(12):1773-1781.

39. Lee E, Chow LY, Leung CM. Metabolic profile of first and second generation antipsychotics among Chinese patients. Psychiatry Res. 2011;185(3):456-458.

40. Moreno C, Merchán-Naranjo J, Alvarez M, et al. Metabolic effects of second generation antipsychotics in bipolar youth: comparison with other psychotic and nonpsychotic diagnoses. Bipolar Disord. 2010; 12(2):172-184
41. $\mathrm{Hu} \mathrm{S}$, Yao M, Peterson BS, et al. A randomized, 12-week study of the effects of extended-release paliperidone (paliperidone ER) and olanzapine on metabolic profile, weight, insulin resistance, and $\beta$-cell function in schizophrenic patients. Psychopharmacology (Berl). Epub April 5, 2013.

42. Bobo WV, Epstein RA, Shelton RC. Olanzapine monotherapy for acute depression in patients with bipolar I or II disorder: results of an 8-week open label trial. Hum Psychopharmacol. 2010;25(1):30-36.

43. Newcomer JW, Meyer JM, Baker RA, et al. Changes in non-highdensity lipoprotein cholesterol levels and triglyceride/high-density lipoprotein cholesterol ratios among patients randomized to aripiprazole versus olanzapine. Schizophr Res. 2008;106(2-3):300-307.

44. Wetterling T. Bodyweight gain with atypical antipsychotics. A comparative review. Drug Saf. 2001;24(1):59-73.

45. Domon SE, Cargile CS. Quetiapine-associated hyperglycemia and hypertriglyceridemia. J Am Acad Child Adolesc Psychiatry. 2002;41(5): 495-496.

46. Meyer JM. Novel antipsychotics and severe hyperlipidemia. J Clin Psychopharmacol. 2001;21(4):369-374.

47. Shaw JA, Lewis JE, Pascal S, et al. A study of quetiapine: efficacy and tolerability in psychotic adolescents. J Child Adolesc Psychopharmacol. 2001;11(4):415-424.

48. Shirzadi AA, Ghaemi SN. Side effects of atypical antipsychotics: extrapyramidal symptoms and the metabolic syndrome. Harv Rev Psychiatry. 2006;14(3):152-164.

49. Manfredi R, Chiodo F. Disorders of lipid metabolism in patients with HIV disease treated with antiretroviral agents: frequency, relationship with administered drugs, and and role of hypolipidaemic therapy with bezafibrate. $J$ Infect. 2001;42(3):181-188.

50. Allison DB, Mentore JL, Heo M, et al. Antipsychotic-induced weight gain: a comprehensive research synthesis. Am J Psychiatry. 1999; 156(11):1686-1696.

51. Gungor O, Kircelli F, Demirci MS, et al. Serum paraoxonase 1 activity predicts arterial stiffness in renal transplant recipients. J Atheroscler Thromb. 2011;18(10):901-905.

52. Wang Y, Fu W, Xie F, et al. Common polymorphisms in ITGA2, PON1 and THBS2 are associated with coronary atherosclerosis in a candidate gene association study of the Chinese Han population. J Hum Genet. 2010;55(8):490-494.

53. Wang M, Lang X, Cui S, et al. Quantitative assessment of the influence of paraoxonase 1 activity and coronary heart disease risk. DNA Cell Biol. 2012;31(6):975-982.

54. Zhao Y, Ma Y, Fang Y, et al. Association between PON1 activity and coronary heart disease risk: A meta-analysis based on 43 studies. Mol Genet Metab. 2012;105(1):141-148.
Neuropsychiatric Disease and Treatment

\section{Publish your work in this journal}

Neuropsychiatric Disease and Treatment is an international, peerreviewed journal of clinical therapeutics and pharmacology focusing on concise rapid reporting of clinical or pre-clinical studies on a range of neuropsychiatric and neurological disorders. This journal is indexed on PubMed Central, the 'PsycINFO' database and CAS.
Dovepress

The manuscript management system is completely online and includes a very quick and fair peer-review system, which is all easy to use. Visit $\mathrm{http}: / / \mathrm{www}$.dovepress.com/testimonials.php to read real quotes from published authors. 